\title{
Gamificação: como jogos e tecnologias podem ajudar no ensino de idiomas. Estudo de caso: uma escola pública do Estado do Amapá
}

\section{Ailton da Silva Pantoja ${ }^{1}$ e Luandierison Marques Pereira ${ }^{2}$}

\author{
1 Bacharel em Sistema de Informação pela Faculdade Estácio Seama. Técnico Laboratório-Informática no IFAP, Brasil. \\ E-mail: ailtonpantojajunior@gmail.com $\$$ http://lattes.cnpq.br/9375232097268672 1 http://orcid.org/0000-0002-4801-2428 \\ 2 Bacharel em Sistema de Informação pela Faculdade Estácio Seama. Técnico Laboratório-Informática no IFAP, Brasil. \\ E-mail: luandierison@gmail.com 19 http://lattes.cnpq.br/1949978021172686
}

RESUMO: Os jogos sempre despertaram a atenção das pessoas e hoje uma técnica que explora os elementos destes para aplicá-los em outros contextos que não são propriamente jogos, vêm contribuindo para uma relação mais participativa e envolvente com o cliente. Neste cenário novos paradigmas de programação são pensados para desenvolver sistemas que sejam atraentes, viciantes e que explorem as habilidades de cada usuário de forma eficiente. Propomos neste trabalho um estudo de caso em uma escola pública, para testar em um cenário real os efeitos de uma ferramenta gamificada, frente ao método tradicional de ensino, para isso vamos apresentar uma ferramenta que ensina idiomas que já é renomada no mercado o Duolingo. Com isso esperamos descobrir os benefícios ou não de se trabalhar com gamificação em sistemas de informação.

Palavras-chave: Gamificação. Desenvolvimento. Games. Motivação.

Games: how games and technologies, can help in language teaching. Case study: a public school of the State of Amapá

ABSTRACT: Games have always aroused the attention of people and today a technique that explores the elements of these for applies - them in other contexts that are not exactly games, have contributing for a Relationship participatory and engaging more with the client. In this scenario new programming paradigms are thought to develop systems that are attractive, and addictive, exploring skills of each user. We propose this work a case study in a public school, to test in a true scenario the effects gamificated tool front traditional teaching method, and for this we're going to introduce a tool that teaches languages already and renowned any market the Duolingo. With that we expect discover benefits or not to work with gamification in Information Systems.

Keywords: Gamification. Development.Games.Motivation.

\section{INTRODUÇÃO}

Atualmente, as tecnologias da informação e comunicação (TIC), estão inseridas no ambiente de ensino e aprendizagem. Existem diversas ferramentas e plataformas diferentes, com diversos recursos digitais, de PC's desktops aos modernos tablets e smartphones. Isso se relaciona com o perfil desta nova geração que crescem jogando vídeo game, eles já veem isso como parte do seu cotidiano, que poderia ser facilmente introduzido ao ambiente de aprendizagem para motivá-los, conforme esclarece Duarte (2014).

Algumas empresas vêm apostando em utilizar recursos de jogos em seus serviços, esse conceito não é tão novo, porém vem ganhando destaque atualmente. A gamificação é basicamente uso de elementos en- 
contrados em jogos em outros contextos que não são jogos em si. Segundo o infográfico apresentado pela empresa MJV (Maurício José Viana), empresa brasileira de tecnologia e inovação, 2.8 bilhões será o tamanho estimado do mercado de gamificação em 2016, além de mencionar que 50\% da geração $Y$, que compreende pessoas com a idade entre 13 a 33 anos de idade, declaram ver a vida real como um vídeo game e que estas pessoas representaram aproximadamente $75 \%$ da mão de obra global até 2025. Diante de um mercado em potencial, e de uso de tecnologias inovadoras, se faz necessário pensar em novo paradigma de desenvolvimento de sistemas que se enquadrem nas novas tendências e que consiga atrair a atenção de um público específico.

O objetivo deste trabalho é mostrar como a gamificação tem grande influência na atenção e no comprometimento do usuário, de forma que o mesmo se sente instigado a usar o serviço, não porque ele é obrigado, mas sim porque ele realmente se sente a vontade para usá-lo. Para isso vamos focar na área de educação, usando como parâmetro uma ferramenta que ensina idiomas em uma plataforma online, e que também dispõe de app para smartphones, o Duolingo. Este trabalho apresenta um estudo de caso em uma escola pública de ensino, onde comparamos o método tradicional de ensino de idiomas aplicado pelo professor(a) na sala de aula versus o ensino de idiomas com o auxílio do Duolingo. E com isso mostrar ou não, o sucesso de usar gamificação em sistemas de informação com o propósito de fortalecer a interação com o usuário.

\section{HISTÓRICO}

De acordo com McGonigal (2010), os jogos sempre fizeram parte da história da humanidade, e ao longo do tempo muitas civilizações participaram de competições importantes para a estruturação social do seu povo. Cerca de 2.500 anos atrás, segundo Heródoto (grande historiador grego), o jogo de dados foi criado pelo rei da Lídia, como medida extrema diante da fome severa que massacrava seu povo, assim o governo estabeleceu uma política, onde foi determinado que em um dia o povo comeria e no outro jogaria, assim poderiam se distrair, pois estariam tão imersos no jogo, fazendo uma atividade prazerosa que "esqueceriam" que não tinham comida pra comer e de acordo com Heródoto essa política perdurou por 18 anos.

Mas o período de escassez se prolongou, levando o rei a dividir seu reino pela metade e jogar um último jogo de dados onde os vencedores iriam ter que sair da Lídia para uma aventura única e procurar uma nova maneira para viver, deixando para trás uma parte do seu povo que poderia viver com os recursos que ainda tinham. E hoje evidências recentes de DNA dos Etruscos que formaram o império romano, mostram que os antigos habitantes da Lídia, podem ter sobrevivido na sua jornada desesperada. A motivação aqui é a de que os jogos ajudaram esse povo a sobreviver, eles salvaram sua civilização através dele. (MCGONIGAL, 2010).

Em 2002, Nick Pelling, programador e pesquisador britânico, usou o termo "gamification" pela primeira vez, mas foi apenas em 2010, quando Jane McGonigal (game design americana) realizou uma palestra no TED (Technology, Entertainment, Design) 
que o termo ganhou destaque. Jane argumentou que dedicamos mais tempo na resolução de problemas do mundo virtual, do que tentando resolver os problemas do nosso mundo. Ela chama a atenção do público, mostrando que se somadas todas as horas gastas pelos jogadores do popular jogo World of Warcraft que foi lançado em 2004, teriam sido gastos 5,93 bilhões de anos na resolução de problemas deste mundo virtual. Um número realmente absurdo, mas que está correto, toda a história da humanidade desdobrou-se em um prazo de tempo menor que esse. E se essas horas fossem gastas resolvendo problemas do nosso mundo?!. Este é o grande desafio da gamificação (VIANNA, 2013).

De acordo com McGonigal (2012), os games atraem cada vez mais pessoas por fazerem um trabalho melhor do que a realidade para atender aos verdadeiros desejos da humanidade.

\section{O QUE É UM JOGO?}

Para que possamos entender melhor o conceito de gamificação, precisamos saber o que é um jogo, de acordo com Crawford (2003) apud Araújo (2012, p. 225), que declara "Você não pode projetar jogos se você não entende o conceito de jogar - e jogar é um comportamento humano complexo e complicado."

Outra definição interessante é a de Huizinga (1980, p. 33):

O jogo é uma atividade ou ocupação voluntária, exercida dentro de certos e determinados limites de tempo e de espaço, segundo regras livremente consentidas, mas absolutamente, obrigatórias, dotado de um fim em si mesmo, acompanhado de um sentimento de tensão e de alegria e de uma consciência de ser dife- rente da 'vida cotidiana'.

Todos esses significados apontam para a existência obrigatória de regras na qual elas são essenciais para a criação de um jogo também defendida por Salen e Zimmerman (2004) apud Araújo (2012, p. 225), “um jogo é um sistema em que os jogadores engajam em um conflito artificial, definido por regras, cujo resultado é quantificável".

Atualmente existem vários gêneros e tipos de jogos, porém podemos destacar 3 (três) principais categorias, são estes: Os Jogos Analógicos, conhecidos por serem um dos primeiros formatos de jogos criados pelo homem que ainda hoje se faz presente, e também propõem uma maior interação entre os jogadores, entre estes estão, jogos de cartas, jogos de tabuleiro, damas, xadrez e etc. Os Jogos Pervasivos são aqueles que exploram uma experiência mais interativa com o jogador, o obrigando a sair do conforto do sofá para fazer movimentos físicos que são capturados por tecnologias como o Kinect, Oculus Rift, Nintendo Wii, dentre outros. E por fim temos os Jogos Digitais, que estão disponíveis nas mais diversas plataformas, como consoles, celulares, computadores e etc. Com uma variedade de jogadores como afirma Vianna (2013).

Destas categorias, os jogos digitais ganharam muita importância nas últimas décadas, segundo Landim Wikerson (2008, p. 1):

Ao que tudo indica, o crescimento exponencial do mundo dos games está longe de encontrar o seu limite. Números do setor apontam que as vendas de consoles, jogos e serviços relacionados a games online hoje ultrapassam os US\$ 60,4 bilhões anuais, podendo chegar a US\$ 75 bilhões até 2015. Para se ter 
uma ideia da relevância desse montante, em 2010 todos os filmes produzidos em Hollywood faturaram pouco mais de US\$ $31,8 \mathrm{bi}$ Ihões.

\section{GAMIFICAÇÃO}

Os jogos exercem uma atração irresistível sobre nós e a capacidade destes de gerar motivação, dedicação e engajamento podem ser usados em inúmeros contextos e propósitos, como por exemplo, na educação, na saúde, no ambiente corporativo e etc.

A Gamificação é uso de mecânicas, dinâmicas e estéticas de games utilizados em outros contextos que não são jogos em si. Quando participamos de um processo gamificado não significa que estamos participando de um jogo necessariamente, mas sim que estamos adquirindo suas características mais eficientes para conseguir os mesmos benefícios alcançados por estes de acordo com Vianna (2013).Ao tratar sobre gamificação, Werbach e Hunter (2012) apud Duarte (2014), "afirmam que o desafio desse processo é usar elementos que normalmente operam no universo dos games e aplicá-los efetivamente no mundo real." (p.3).

O objetivo da gamificação é o de criar ou adaptar a experiência do usuário a um determinado serviço, processo ou produto com a intenção de liberar emoções positivas, motivar, engajar as pessoas, explorar habilidades ou propor benefícios como recompensas físicas ou virtuais a realização de tarefas. Sem dúvida os jogos ganharam uma importância significativa em nossas vidas, Gladwell (2008), propõem a teoria de que quando nos dedicamos, fazemos um trabalho duro, sobre qualquer coisa, por exemplo, tocar violão, jogar futebol ou estudar programação por um período de tempo equivalente a 10 mil horas, seríamos tão bons naquilo que teríamos uma habilidade equivalente a uma pessoa considerada fora de série.

As pessoas estão cada vez mais inserindo os jogos em suas atividades cotidianas, a presença destes é notável, seja na fila de um banco ou nas viagens de ônibus acaba sendo perceptível a necessidade de ocupar o tempo com algo dinâmico e interativo. Se calculássemos essas horas destinadas aos jogos, atingiríamos o equivalente a $10 \mathrm{mil}$ horas em um período de tempo relativamente curto.

Cada vez mais as empresas vêm investindo em gamificação, para atrair novos clientes e fidelizar os antigos, além de motivá-los a colaborar na construção do conhecimento, como no caso do Duolingo, que combina tecnologia, gamificação, com o ensino de idiomas.

\section{O DUOLINGO}

O Duolingo une uma plataforma online de ensino de idiomas, como um serviço de tradução colaborativa, que combina tecnologia com gamificação. O Duolingo dispõe de vários idiomas em seu catálogo de ensino, o aluno além de aprender um novo idioma de forma gratuita e divertida, ajuda na tradução de sites e documentos online. Inicialmente o sistema propõe módulos simples sobre o idioma escolhido pelo usuário e conforme o progresso do mesmo, ele desbloqueia novas unidades, com conteúdo avançado. As lições são como pequenas fases, cada erro faz o usuário dar um passo atrás na conclusão dela, ao completar ele ganha pontos, que são usados para gerar 
rankings e gráficos com o progresso do aluno. No Duolingo o usuário aprende a escrever, a falar e a compreender um novo idioma jogando.

O sistema é gratuito e está disponível em diferentes dispositivos e plataformas, tais como: no computador, smartphone ou tablet. $O$ usuário então pode aprender um novo idioma em qualquer lugar, seja no ônibus, na fila de um banco e etc. A seguir mostraremos algumas imagens com as telas do sistema, para uma melhor compreensão do mesmo.

Figura 1 - Painel principal com os módulos.

Figure 1 - Main painel with stages

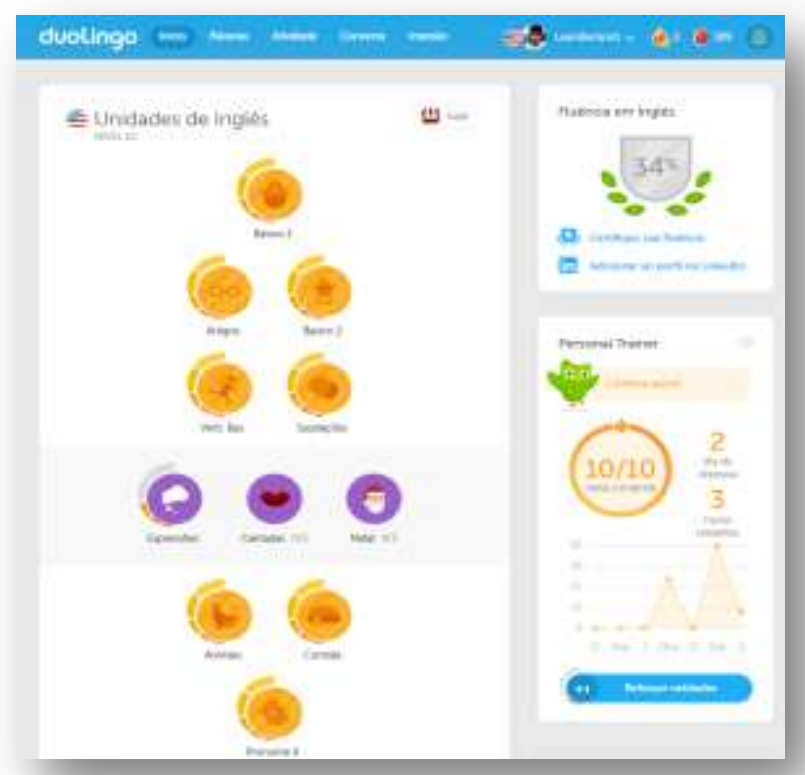

Fonte: https://www.duolingo.com/

Na figura 1, vemos o painel do principal do usuário, ao logar na plataforma. Estas unidades em forma de círculos contêm assuntos que estão organizados em níveis, que vão ficando douradas com o progresso dos usuários, após o tempo sem fazer determinada unidade, ela deixa de ser dourada, fazendo o usuário refazê-la. Dentro de cada unidade temos lições que combinam diversas técnicas, como tradução de textos, tradução a partir de imagens, tradução por fala, e tradução através da escuta. Como podem ser vista nas figuras a seguir.

Figura 2 - Lições da Unidade Básico I.

Figure 2 - Lessons of the basic stage I.

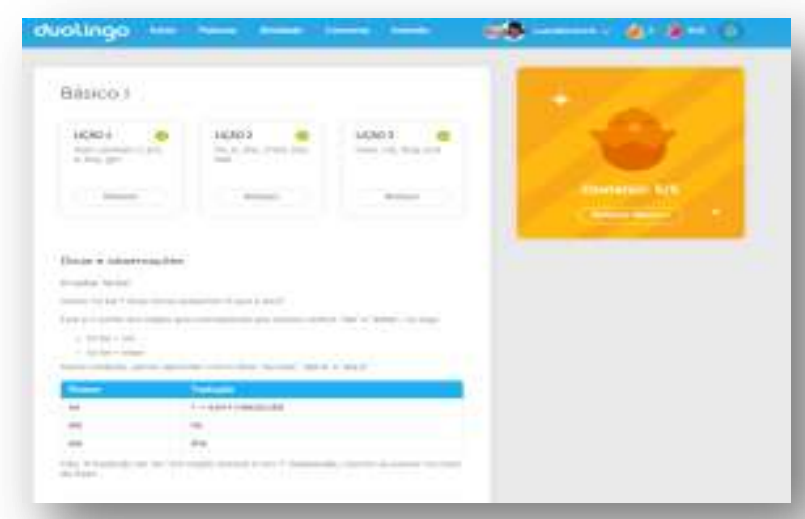

Fonte: https://www.duolingo.com/

Ao acertar uma questão, é emitido um sinal sonoro positivo, e a resposta é corrigida em uma cor verde, além de uma barra de progresso marcar o avanço da lição. $O$ contrário acontece quando se erra uma questão. Veja na figura 3 e 4 respectivamente.

Figura 3 - Lição 1, Básico I.

Figure 3 - Lesson 1, Basic I.
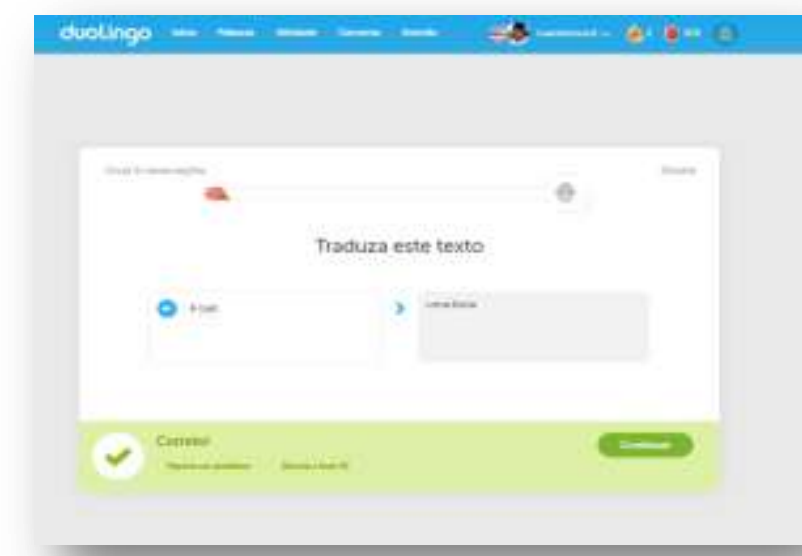

Fonte: https://www.duolingo.com/ 
Figura 4 - Lição 1, Básico I.

Figure 4 - Lesson 1, Basic I.

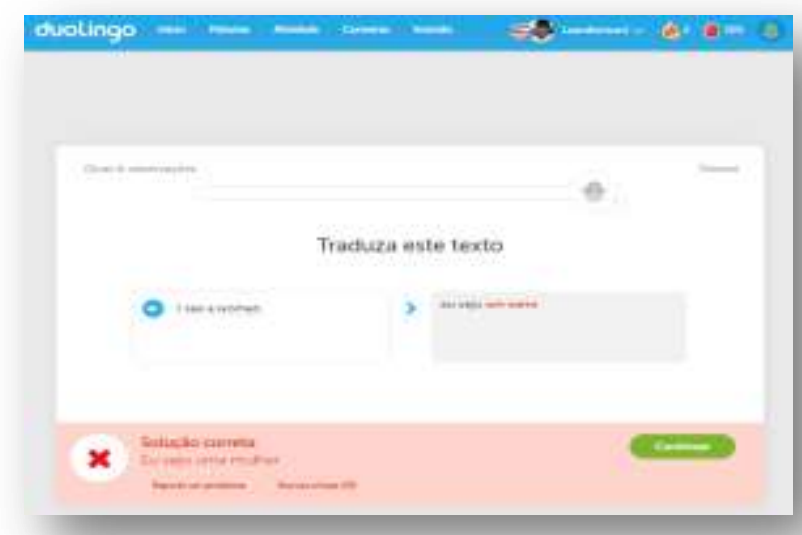

Fonte: https://www.duolingo.com/

Ao terminar cada lição, o usuário recebe pontos, que servem para gerar rankings entre os amigos que ele possui na plataforma, além de marcar sua ofensiva, que são os dias consecutivos que o usuário passa estudando o idioma. Também é fornecido alguns lingots (moeda virtual da plataforma) que serve para comprar novas unidades com assuntos inéditos e outros recursos como bloqueio de ofensivas, prática com cronômetro entre outros.

Esse sistema de ofensivas e rankings estimula o usuário, a realizar uma competição tanto pessoal, no caso das ofensivas, quanto com os amigos que estão no seu quadro de ranking. Figura 5 e 6.
Figura 5 - Rankings.

Figure 5 - Rankings.

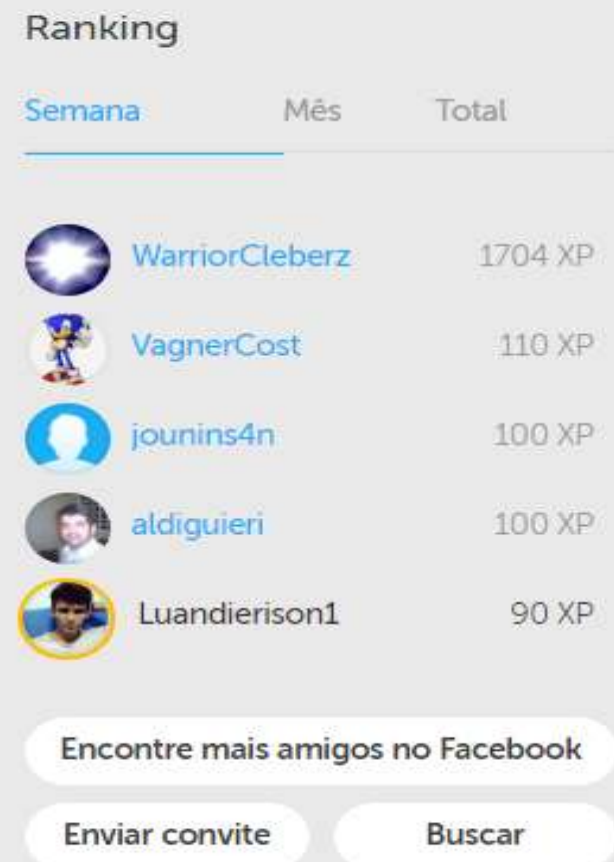

Fonte: https://www.duolingo.com/

Figura 6 - Número de Ofensivas e Lingots.

Figure 6 - Numbers of Offensives and Lingots.

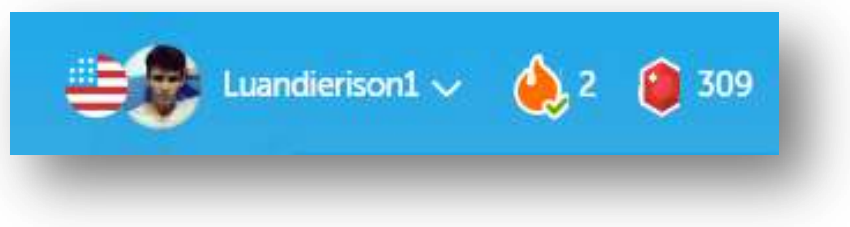

Fonte: https://www.duolingo.com/

\subsection{Duolingo para escolas}

Recentemente o Duolingo lançou uma extensão de sua plataforma que possibilita aos professores acompanhar o progresso de seus alunos em um só lugar. Segundo Luis Von Ahn, cofundador do Duolingo, (2015, p. 1): 
A meta é proporcionar uma experiência de aprendizado personalizada com feedback imediato para cada aluno e professor na sala de aula. Isto permitirá que professores tenham mais tempo para se concentrar em conceitos difíceis, responder perguntas ou ajudar alunos que estão ficando para trás.

Com um painel organizado o professor pode gerenciar os alunos e ver o progresso dos mesmos através da resolução das lições e entender suas dificuldades e identificar quais alunos precisam de atenção especial ou qual assunto os alunos estão com dificuldade. Vejamos o painel de gerenciamento na figura 7.

Figura 7 - Painel de Gerenciamento dos alunos.

Figure 7 - Student Management Panel.

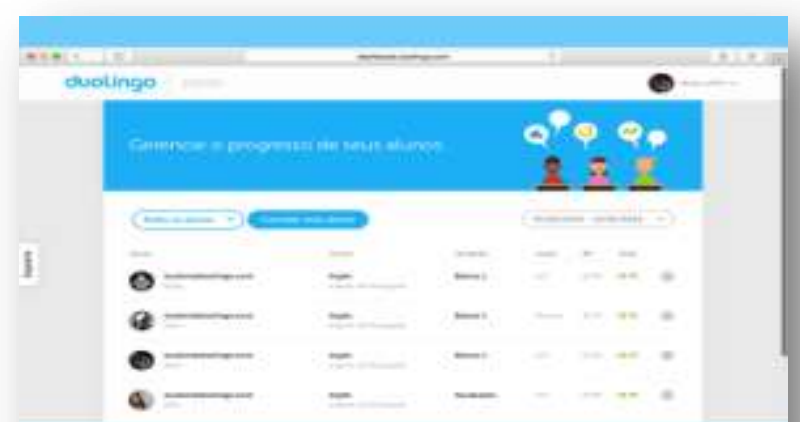

Fonte: https://schools.duolingo.com/

Algumas instituições de ensino de San José (capital da Costa Rica) e da Guatemala usam o Duolingo como ferramenta para auxiliar no ensino de idiomas, visto que essas escolas carecem de profissionais com uma boa qualificação em um idioma estrangeiro. Entretanto, o Duolingo foi concebido para uso individual, e os professores não tinham como avaliar de forma eficiente o progresso dos alunos. O Duolingo para Escolas, surgiu justamente para resolver este problema, possibilitando o professor ter o feedback maior sobre o seu aluno, entender suas dificuldades e etc. (SOUZA, 2015).

\section{METODOLOGIA}

Realizamos uma pesquisa em uma escola pública na cidade de Macapá-AP, com 4 turmas do 60 ano, conversamos com a diretora do colégio, a mesma nos orientou a trabalhar com estas turmas, pelo fato de elas estarem iniciando os estudos em um novo idioma e sentirem uma maior dificuldade no aprendizado por ser algo novo para elas. Também consultamos os professores de idiomas da escola e os mesmos aprovaram a decisão da diretora. A ideia da pesquisa consiste em avaliar como os alunos se saem usando um sistema que ensina idioma de forma gamificada, ou seja, que usa recursos de jogos, frente ao tradicional método de ensino ministrado pelo professor em sala de aula. E a partir daí colher dados sobre a eficácia ou não do uso da gamificação em sistemas de informação com o intuito de atrair, fidelizar e contribuir com a geração de conhecimento para os seus usuários.

A primeira etapa da pesquisa consistia em fazer um workshop com os dois professores, que ministram idioma na escola para mostrar o Duolingo e explicar seu funcionamento, depois em conjunto com estes montamos um teste, que denominamos de "Teste de Nivelamento" Apêndice I, contendo 15 questões de cada assunto, totalizando 30 questões que foram extraídas do próprio Duolingo. Esse teste engloba dois módulos do Duolingo com os assuntos verbo to be e artigos, ambos já explanados pelos professores no bimestre atual. Depois de apresentado o Duolingo e o nosso objetivo com este trabalho, dividimos os profes- 
sores, para preservar os participantes da pesquisa, resolvemos não citar os nomes dos participantes desta, denominaremos aqui os professores de professor 1 e 2, onde o professor 1 ficou com as turmas que iriam aprender os assuntos citados anteriormente com o auxílio do Duolingo e o professor 2 ficou encarregado de ministrar os assuntos da maneira tradicional. E ao final ambos passariam o teste de nivelamento para avaliar o aprendizado dos alunos.

As turmas envolvidas na pesquisa foram as turmas 621-A, 622-A, 611-A e 613-A, sendo as duas primeiras trabalhadas as aulas com abordagem pelo método tradicional e as outras duas com o auxílio do Duolingo. Por questões de ética não mencionaremos os nomes dos alunos.

\subsection{Dos resultados}

A pesquisa foi realizada com apenas uma aula para cada turma, os alunos levaram o teste como dever de casa e trouxeram na aula seguinte. A correção foi feita juntando as turmas que fizeram a aula de maneira tradicional totalizando o número total de questões com acertos, erros e deixadas em brancos, e também o mesmo realizado com as turmas que tiveram o apoio do Duolingo. Também optamos por eliminar alguns testes das turmas que não utilizaram o Duolingo de maneira aleatória, pois participaram mais alunos e precisávamos igualar o número de alunos das turmas com o Duolingo. Observe os resultados a seguir, Figura 8.
Figura 8 - Resultado Geral

Figure 8 - Overall result

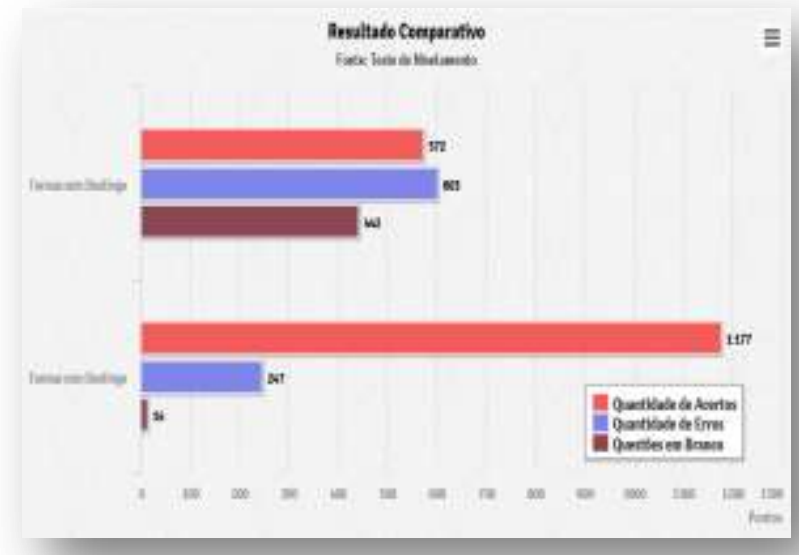

Fonte: pesquisa de campo, 2016

Analisando o gráfico acima, podemos perceber que a diferença entre as turmas, de maneira geral foi bastante grande, o total de acertos da turma com Duolingo foi mais que o dobro da turma sem Duolingo, 1.177 e 572 acertos respectivamente. O total de erros também se mostrou menor com 603 para a turma sem Duolingo e 242 para a turma com Duolingo. Outro fator bastante curioso é número de questões deixadas em branco nas turmas com o uso de gamificação tivemos apenas 14 questões deixadas em branco versus 442 da turma com aprendizado tradicional.

\section{CONSIDERAÇÕES FINAIS}

A pesquisa realizada neste trabalho mostrou que o uso da gamificação merece uma atenção especial, no desenvolvimento de sistemas e na construção de novos paradigmas, pois a mesma consegue atrair as pessoas e as motiva-las a resolver problemas que de outra maneira não resolveriam ou não trabalhariam com a mesma atitude perante as dificuldades encontradas. Os alunos que aprenderam com o auxílio do 
Duolingo, se mostraram mais dedicados deixando poucas questões em branco, além de acertarem mais questões que os demais.

Os professores participantes da pesquisa elogiaram o trabalho, pois segundo eles nenhuma outra pesquisa do tipo tinha sido realizada na escola e com uma aceitação tão boa por parte dos alunos, eles viram nesta ferramenta a oportunidade de maximizarem o aprendizado de seus alunos. Porém as escolas públicas do estado de maneira geral ainda carecem de recursos tecnológicos, como laboratórios e uma internet de qualidade. Tivemos algumas dificuldades com relação à internet do laboratório da escola, pois o sinal era péssimo, na ocasião levamos um aparelho roteador independente com acesso a internet e junto com um notebook e um data show, foi possível realizar a aula gamificada. Os professores ficaram interessados na ideia que ficaram de falar com a diretora da escola sobre a viabilidade de comprar um aparelho de internet igual ao que levamos para auxiliar nas aulas, pois é uma solução simples e barata.

Quando criamos algo gamificado, estabelecemos uma motivação que vai além do simples fato de resolução de problemas, pois acabamos entrando em uma competição tanto interna onde pensamos se conseguimos resolver tal problema, quanto externa que são contra nossos amigos, assim de maneira saudável promovendo a disseminação do conhecimento, ou a valorização da marca, ou ainda a venda de um determinado produto, serviço e etc. Precisamos desenvolver sistemas pensando no usuário, que abordem as novas tecnologias de maneira mais eficaz e eficiente, e com certeza a gamificação pode contribuir para este cenário.

\section{REFERÊNCIAS}

ARAUJO, M. H. de. Jogo, serious games e boas práticas: uma análise dos aspectos conceituais do jogo Space Cross da Volskagen. Trabalho de Conclusão de Curso. Florianópolis: Design/UFSC Florianópolis:

DUARTE, G. B. O processo de gamificação e a aprendizagem de línguas pelo viés da Complexidade. Anais... Buenos Aires, 2014. GLADWELL, M. Fora de Série (Outliers). Rio de Janeiro: Sextante, 2013.

HUIZINGA, J. Homo ludens: o jogo como elemento da cultura. Editora da Universidade de S. Paulo, Editora Perspectiva, 1971. LANDIM, W. O tamanho da indústria dos vídeo games [infográfico]. Tecmundo: 21 de agosto de 2008. Disponível em: <http:// www.tecmundo.com.br/infografico/9708-o -tamanho-da-industria-dos-video-games-in fografico-.htm>. Acesso em: 21 abr. 2016. MCGONIGAL, J. A realidade em jogo: por que os games nos tornam melhores e como eles podem mudar o mundo. Rio de Janeiro: Best Seller, 2012.

MCGONIGAL, J. Jogando por um mundo melhor. TED Ideas Worth Spreading, 2015. 20min e 31seg. Disponível em: <https://ww w.youtube.com/watch?v=dE1DuBesGYM>. Acesso em: 17 nov. 2015.

SOUZA, R. Executiva brasileira coloca o Duolingo nas escolas da América Latina. Tecmundo: 02 de fevereiro de 2015. Disponível em: <http://www.tecmundo.com.br/educa cao/73487-executiva-brasileira-coloca-duoli ngo-escolas-america-latina.htm>. Acesso em: 25 abr. 2016.

SALEN, K.; ZIMMERMAN, E. Rules of play: game design fundamentals. MIT press, 2004.

YSMAR, V. et al. Gamification, Inc. Como reinventar empresas a partir de jogos. 1.Ed 
Rio de Janeiro: MJV Press, 2013.

MJV Technology \& Innovation, Infográfico: gamificação para negócios. Disponível em: <http://www.mjv.com.br/biblioteca/veja-n osso-infografico-de-gamificacao-para-nego cios> Acesso em: 05 abr. 2016.

VEJA Abril, Da Redação, Duolingo lança plataforma de ensino de idiomas para escolas. Disponível em: <https://veja.abril.com.br/ tecnologia/duolingo-lanca-plataforma-deensino-de-idiomas-para-es colas/> Acesso em: 31 maio 2016.

\section{APÊNDICE \\ TESTE DE NIVELAMENTO}

\section{EXERCÍCIO}

1 Traduza as seguintes frases usando como base o texto anterior sobre verbo "tobe".

I am a man

I see a boy

Eu sou um homem

Sheis a woman

$\mathrm{He}$ is a man

Eu sou uma criança

A boy and a girl

I have a ball

Eu tenho uma bola

I see a girl

2 Complete as frases usando o verbo to be de maneira correta.

$\mathrm{He}$ here.

I___ a person.

She ___ intelligent.

I a child.

She a woman.

3 Resolva os exercícios sobre artigos, de acordo com o assunto apresentado em sala de aula.

I have apple.
_ _ _ orange and a girl.

- _ apple.

- - animal

_-_ elephant.

I have ___ animal.

___ dog and _ _ _ elephant.

_- _ orange.

\section{Traduza as seguintes frases:}

Eu vejo uma maça.

Eu tenho um animal.

Um gato.

Um cachorro e um gato.

Eu vejo um animal.

Uma mulher e uma laranja.

Uma laranja e uma garota.

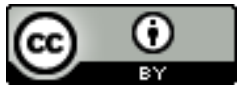

License information: This is an openaccess article distributed under the terms of the Creative Commons Attribution License, which permits unrestricted use, distribution, and reproduction in any medium, provided the original work is properly cited.

Artigo recebido em 01 de junho de 2016.

Avaliado em 15 de dezembro de 2017.

Aceito em 30 de janeiro de 2018.

Publicado em 25 de maio de 2018.

Como citar este artigo (ABNT):

PANTOJA, Ailton da Silva; PEREIRA, Luandierison Marques. Gamificação: como jogos e tecnologias podem ajudar no ensino de idiomas. Estudo de caso: uma escola pública do Estado do Amapá. Estação Científica (UNIFAP), Macapá, v. 8, n. 1, p. 111-120, jan./abr. 2018. 